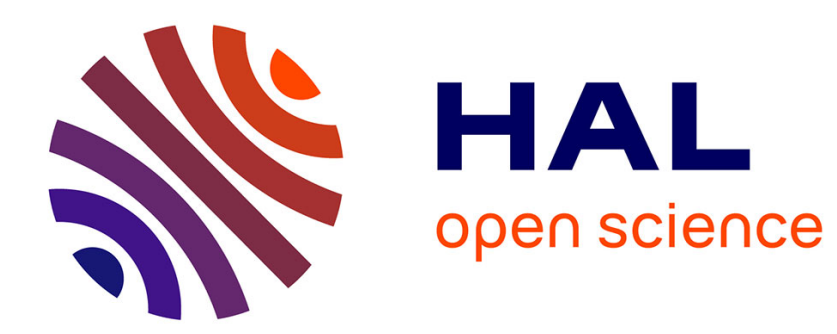

\title{
GENERATION OF cw FIR RADIATION USING 2- AND 3-PHOTON INTERACTIONS
}

\author{
C. Weiss, G. Willenberg
}

\section{To cite this version:}

C. Weiss, G. Willenberg. GENERATION OF cw FIR RADIATION USING 2- AND 3PHOTON INTERACTIONS. Journal de Physique Colloques, 1981, 42 (C8), pp.C8-97-C8-103. 10.1051/jphyscol:1981812 . jpa-00221707

\section{HAL Id: jpa-00221707 https://hal.science/jpa-00221707}

Submitted on 1 Jan 1981

HAL is a multi-disciplinary open access archive for the deposit and dissemination of scientific research documents, whether they are published or not. The documents may come from teaching and research institutions in France or abroad, or from public or private research centers.
L'archive ouverte pluridisciplinaire HAL, est destinée au dépôt et à la diffusion de documents scientifiques de niveau recherche, publiés ou non, émanant des établissements d'enseignement et de recherche français ou étrangers, des laboratoires publics ou privés. 
GENERATION OF CW FIR RADIATION USING 2- AND 3-PHOTON INTERACTIONS

C.O. Weiss and G.D. Willenberg

Physikalisch-Technische Bundesanstalt, Bundesallee 100, 3300 Braunschweig, F.R.G.

Abstract.- Recent experiments aimed at generation of FIR continous radiation with 1 imited tunability utilizing 2-photon and 3-photon transitions are described.

Coherent $\mathrm{cw}$ radiation sources in the far infrared, the wavelength region between 20 and $1000 \mathrm{um}$ took a step forward in the early $70 \mathrm{~s}$. After being 1 imited to a few laser transitions in $\mathrm{HCN}$ and $\mathrm{H}_{2} \mathrm{O}$ for a number of $y=a r s$, the discovery of the technique of optical pumping of molecules /1/ in 1970 gave rise to an activity, which up to now has provided some 2000 laser wavelength in the FIR $/ 2 /$. (Fig. 1) while the efforts where first directed to the generation of new wavelengths and appropriate resonator design $/ 21 /$, interest arose subsequently in the physics of these systems. Early work attempted to describe these lasers on a basis of rate equation models / $/$ motivated to understand and possibly remedy the low efficiency of these systems. This work recognized the role of collision processes /4/. However in 1975 it was suggested /5/ that since one is dealing with coherent excitation, a rate equation treatment is inadequate. Work began than to treat the lasers semiclassically i.e. treating the molecules as quantum systens and the radiations as classical fields. (Fig. 1) The theoretical treatment was based on earlier spectroscopic work on coherently driven 3-1evel systems /6/ using the density matrix formalism and generally applying a generalized rotating wave approximation. These calculations predicted coherence effects like anisotropic gain and line splitting due to AC-Stark effect. These two effects could be experimentally observed in $/ 7 / / 8 /$.

A quantitative comparison between calculated and measured laser properties such as gain saturation as functions of the relevant parameters gas pressure, field strengths, and field frequencies yielded satisfactory agreement for $\mathrm{CH}_{3} \mathrm{OH}$ lasers $/ 9 / / 10 /$ and in particular of 
$\mathrm{NH}_{3}$ lasers /11/ for which the molecular parameters such as transition dipole moments, level energies, partition function, line broadening parameters which enter the calculations are known best.

It appeared therefore that the theoretical treatment could be trusted to properly describe 3 level coherently pumped lasers and that it could be used to predict the feasibility of new systems.

1. Since the theoretical treatment contains no limitations as to which degree the fields have to be resonant with the molecular transitions, it was possible to investigate theoretically the process of stimulated Raman scattering. Calculations showed that the two-photon process of stimulated Raman scattering (SRS) (Fig. 2) which had already been used for FIR generation using pulsed MW power pump sources $/ 12 /$ could be made strong enough, even when using $\mathrm{cw}$ pump sources 5 orders of magnitude weaker, to provide Stimulated Raman Scattering gain adequate for the realisation of CW Raman lasers. A SRS FIR CW laser was experimentally demonstrated $\left.{ }^{+}\right) / 13 /$ and after this the rules of the game were known so that additional systems could be made to work /14/. Gain measurements of the FIR Raman laser/11/finallyconfirmed the adequacy of the 3-level theory also for Raman lasers.

These Raman systems show some interesting features compared to resonant1y pumped systems

a) Their emission Iine frequency can be tuned by the pump frequency and

b) The FIR emission line width is approximately equal to the IR Doppler width and thus by an order of magnitude larger than for resonant1y pumped systems. (Both as a consequence of the absorptionemission process (Fig. 2) being two-photon resonant)

c) The SRS lasers are insensitive to molecular collisions since no population inversion in the usual sense is required.

The feature b) has been utilized technically already providing FIR laser frequencies $100 \mathrm{MHz}$ apart for beat frequency modulated plasma interferometer, for Tohamak diagnostics /15/

+) This constitutes the first demonstration of a cW SRS gas laser. Shortly after the publication of /13/ a SRS cw gas laser was realised by A. Brillet /20/ using optical pumping of electronic transitions in $\mathrm{Li}_{2}$ dimers. 
Feature $C$ allows operation of these systems at higher pressure and consequently higher emitter density, limited only by the collision broadening of the nearby resonant absorbing FIR transition.

The gain saturation behaviour of sRS lasers differs markedly from resonantly pumped systems since gain saturation is only reached by two-photon saturation. Thus the gain saturation intensities are typically 1 - 2 orders of magnitude higher - possibly making SRS lasers more efficient converters from pump to FIR radiation.

2. Optical pumping of molecules by IR lasers relies on close coincidences of lines of suitable IR pump lasers with absorption lines of poler molecules. Although a large number of such coincidences was found using a variety of molecules frequency-tuneability of the pump radiation source is of course desirable. E.g. no pump coincidence exists between the FIR laser molecule with the best properties ${ }^{14} \mathrm{NH}_{3}$ and the regular $\mathrm{CO}_{2}$-laser. As there seems to be little prospect for widely tuneable IR $\mathrm{cw}$ lasers with powers of several tens of watts, another application of two-photon interactions appeared to be promising. A two-photon transition involving an IR photon (fixed frequency) and a microwave (MW) photon (tuneable frequency) can be utilized as the pump source, if it can be made strong enough (Fig. 3). Estimates showed that $\mathrm{CW} 2$-photon pumping of $\mathrm{NH}_{3}$ laser transitions should be possible using pump intensities of $10 \mathrm{~W} / \mathrm{cm}^{2} \mathrm{IR}$ and $1 \mathrm{~W} / \mathrm{cm}^{2} \mathrm{MW}$.

An experiment was undertaken which successfully demonstrated the first cw two-photon pumped laser $/ 16 /$. The key element in this experiment is the FIR laser resonator which was chosen to be of the circular metallic waveguide type (Fig. 4). This resonator can act at the same time as an overmoded FIR waveguide resonator of low loss and as a MW resonator to resonantly enhance and confine to a small volume the $M W$ field. Coupling of the MW to the resonator could be done without substantially increasing the FIR resonator losses using $\lambda / 2$-slit coupling through the waveguide side wa11. With this system two-photon pumping in $\mathrm{cw}$ mode was demonstrated of a number of $\mathrm{NH}_{3}$ FIR laser transitions. $/ 14 /$

Apart from demonstrating two-photon pumping of $\mathrm{cw}$ laser transitions for the first time, these experiments yield lasers which are electrically modulatable in amplitude and in frequency because the laser process involves a MW-field, which is easily electrically controlled. 
3. A combination of the SRS laser technique with the two-photon pumping technique suggests itself. This would be a two-photon pumped Raman Laser (also known as Hyper-Raman Laser) operating by a threephoton process Fig. 5). A two-photon pumped laser would be converted into a Hyper-Raman Laser simply by deturning the MW-frequency from the two-photon pump resonance.

of course the Hyper-Raman gain will be smaller compared to the gain of a 2-photon pumped laser by roughly the same factor by which SRS gain is smaller than gain of a resonantly single photon-pumped system. This gain decrease will have to be compensated for by an increase in pump field strengths.

Evidently the laser emission of a Hyper-Raman laser would be tuneable in frequency (by tuning the MW-frequency) due to the fact that the process is 3-photon resonant. Realization of tuneable FIR cW laser is of course a challenging goal. In order to know the pump power requirements for a $\mathrm{cw}$ Hyper-Raman laser we have extended the semiclassical treatment of 3-level systems interacting with 2 coherent fields to a 4 level system interacting with 3 coherent fields. $)$

The calculations show a number of interesting physical features of coherently driven 4-level systems such as AC-Stark Splitting of the Raman emission line, 2-photon-AC-Stark Splittings and-shifts. Pump fields of $100 \mathrm{~W} / \mathrm{cm}$ intensity will be required for a few percent $/ \mathrm{m}$ Hyper-Raman gain, $1 \% / m$ being the FIR laser threshold gain of our experimental system. ${ }^{++}$)

+) It should be mentioned that we had to restrict the calculations to the case in which all field polarizations are parallel since for orthogonal polarizations interference can occur between the transitions between the various magnetic sublevels, giving rise to AC-Hanle effects induced by one-photon /19/ and two-photon level shifts and splittings. Thus orthogonal polarizations would require the treatment of a manylevel system and this exceeds reasonable computer times.

++ Interesting experiments could be done to observe multiphoton coherent transients in 4-level systems by pulsing the MW field. 
There are other schemes which could be used to generate tuneable FIR CW laser radiation in 4-level systems e.g. by resonant singlephoton pumping and inducing two-photon transitions involving the FIR radiation and a microwave (Fig. 6). Tuning the MW would then tune the frequency of the FIR radiation. An experiment which we performed on a 4-level system in $\mathrm{HCOOH} / 17 /$ yielded very limited FIR tuneability due to the low gain in $\mathrm{HCOOH}$ which results from the large partition function of this asymmetric molecule/18/. A proper molecule for this purpose: simple symmetry for low partition function and accessible microwave transitions in the excited vibrational state has yet to be found.

\section{$\underline{\text { References }}$}

$11 /$ CHANG T. Y., BRIDGES T. J., Opt. Comm. 1 (1970) 423

/2/ KNIGHT D. J. E., National Physical Laboratory (England) Report Qu. 45 (1981)

/3/ HODGES D. T., TUCKER J. R., HARTWICK T. S., Infrared Phys. 16 (1976) 175

/4/ WEISS C. 0., IEEE Journa1 Quant.E1. QE-12 (1976) 580

/5/ SELIGSON D., DUCLOY M., LEITE J. R. R., SANCHEZ A., FELD M. S., IEEE Journ. Quant. E1. QE-13 (1977) 468

/6/ FELD M. S., JAVAN A., Phys. Rev. 177 (1972) 899

/7/ HEPPNER J., WEISS C. O., Opt. Comm. 21 (1977) 324. see a1so/9/

18 , HEPPNER. J., WEISS C. O., PLAINCHAMP P., opt. Comm. 23 (1977) 381

/9/ HEPPNER J., WEISS C. 0., HÜBNER U., SCHINN G., IEEE Journ. Quant. E1. QE-16 (1980) 392

/10/ HEPPNER J., HÜBNER U., IEEE Journ. Quant. E1. QE-16, (1980) 1093

/11/ MARX R., HÜBNER U., ABDUL-HALTM I., HEPPNER J., NI Y. C., WILLENBERG G. D., WEISS C. O., IEEE Journ. Quant. EI. $\underline{Q E-17}$ (1981) 1123

/12/ BIRON D. G., TEMKIN R. J., LAX B., DANLEY B. G., Opt Lett. 4 (1979) 381

/13/ Willenberg G. D., HÜBNer U., hePPNER J., Opt. Comm. $\underline{33}$ (1980) 193

/14/ WILlenBerg G. D., Opt. Lett. $\underline{6}$ (1981) 372

/15/ HEPPNER J., priv. communication

$/ 16 /$ WILlenberg G. D., Weiss C. O., JONES H., App1. Phys. Lett. 37 (1980) 133

/17/ DANGOISSE D., Deldalle A., GLORIEUX P., Journ. Chem. Phys. $\underline{69}$ (1978) 5201

/18/ WILLENBERG G. D., unpublished results 
/19/ Delsart C., KElleR J. C., KAFTANDiJAN V. P., Opt. Comm. $\underline{32}$ (1980) 406

/20/ MAN-PICHOT C., BRILLET A., IEEE Journ. Quant. EI. QE-16 (1980) 1103

/21/ HEPPNER J., WEISS C. O., Appl. Phys. Lett. $\underline{33}$ (1978) 590
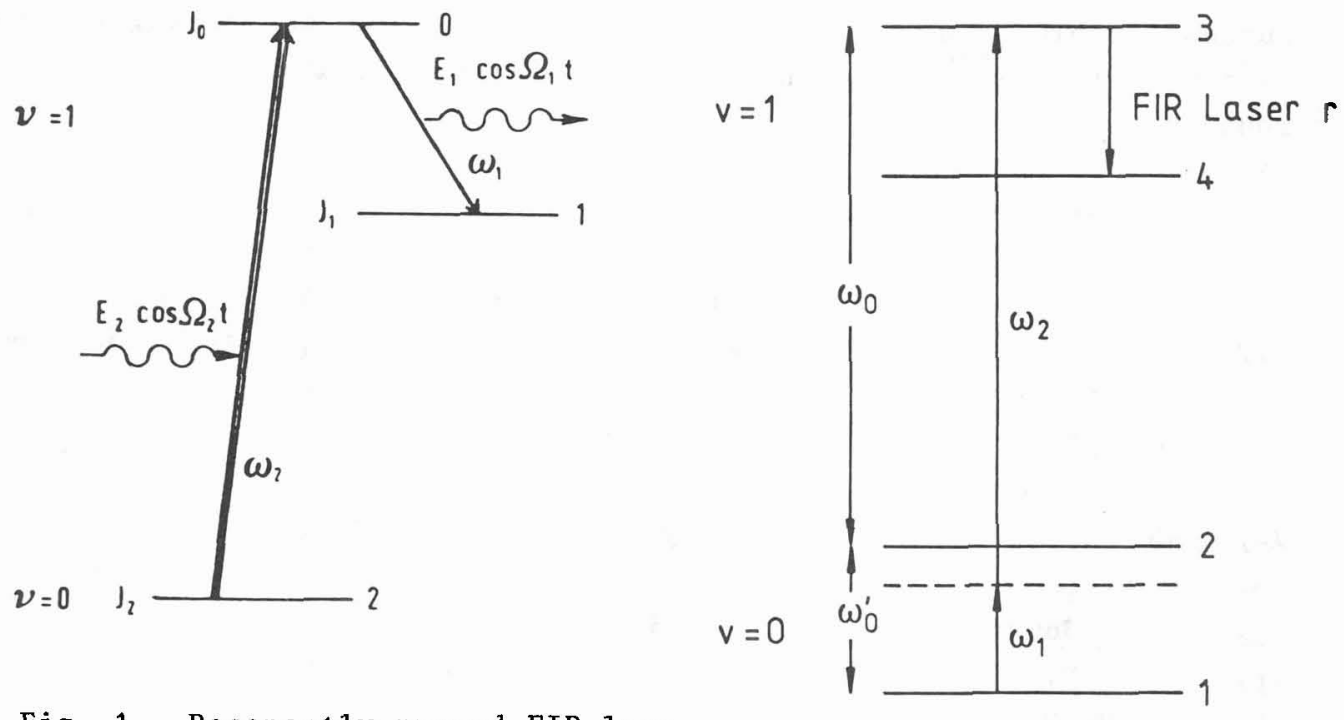

Fig. 1 Resonant1y pumped FIR lase

Fig. 3 Two-photon pumped laser

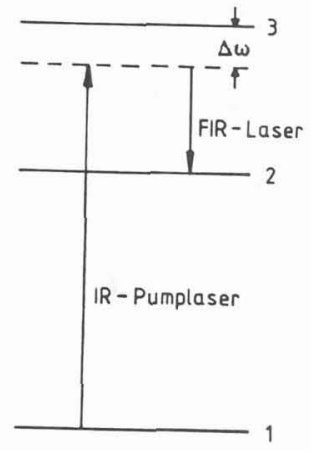

Fig. 2 Stimulated Raman scattering laser 


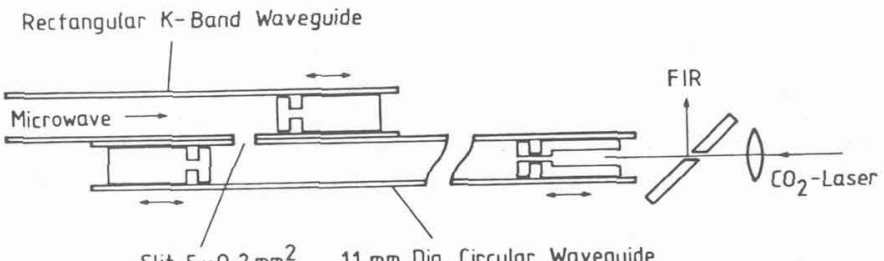

Slit $5 \times 0.2 \mathrm{~mm}^{2} \quad 11 \mathrm{~mm} \mathrm{Dia.} \mathrm{Circular} \mathrm{Waveguide}$

Fig. 4 Waveguide resonator used for two-photon cw pumping of FIR laser transitions

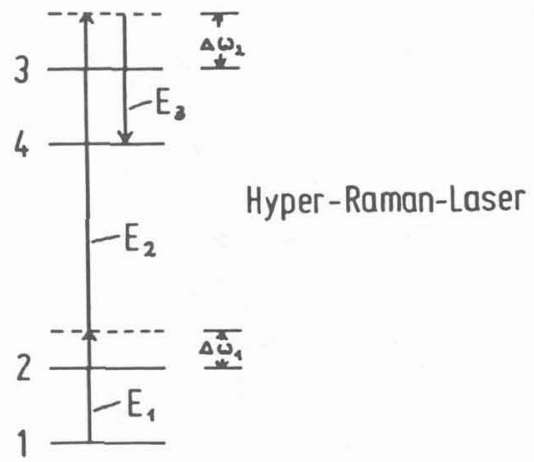

Fig. 5 Hyper-Raman-scattering laser

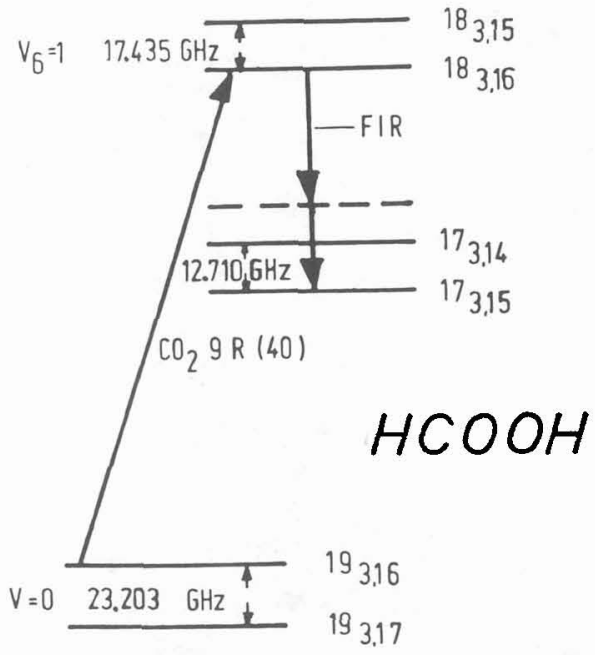

Fig, 6 Energy level scheme for generation of tuneable FIR radiation using a FIR-MW two-photon transition. 